\title{
Genomics, Gene Editing and Biologics: The Bolsters of the New Medical Paradigm
}

\author{
M Dahmani Fathallah* \\ Department of Life Sciences, Arabian Gulf University, Bahrain
}

Submission: July 13, 2017; Published: July 31, 2017

*Corresponding author: M Dahmani Fathallah, Department of Life Sciences, Medical Biotechnology Program, Arabian Gulf University, Manama, Bahrain, Email: d.fathallah@agu.edu.bh

\section{Introduction}

In the dawn of this new century, advances in our understanding of the intricate molecular mechanisms of human life in health and disease states are introducing a paradigm shift in medicine. Disruptive innovations in the way diagnosis, prevention and therapy of most alienating diseases will be carried out, are underway. Three major technical developments in genomics, biological drugs design and gene editing are significantly reshaping the medical landscape. These developments are the results of the translation of a significant amount of scientific knowledge and technological advances into medical practices. This knowledge was accumulated in the fields of genetics and from the unraveling of the human genome [1], in biotechnology with the discovery of a more accurate ways to edit genes and in genetic engineering with the industrial production of powerful biological products (the "biologics") for the treatment of a variety of pathological conditions, ranging from cancer to chronic diseases.

\section{Genomics}

Genomics is the study of the genomes (genes+chromosomes) particularly the entire set of genes that are needed for the development and functioning of each cell of every living organism. Genomics refers to the analysis of a genome anatomically (sequences and organization) [2] and physiologically (expression and regulation) [3]. Genomics has evolved as a medical science and is becoming applied to the medical practice following the automation of the original set of enabling technologies such as gene cloning, DNA sequencing and DNA typing and profiling which emerged concomitantly with the completion of the human genome project [4]. The novel generation sequencing of DNA and RNA [5,6] combined with powerful computing analysis tools made all the patient genetic data at reach of the clinician. The latest DNA typing technologies allow timely genome wide scans [7]. Hence, medical applications for better diseases' diagnosis, treatment, and prevention" are rapidly developing.
Numerous translations of genomics into medicine practice are recorded among which the following:

i. The application of up to 50 tests for the diagnosis of inherited, treatable genetic diseases in newborn screening programs [8].

ii. The use of Pharmacogenomics which involves using the data of an individual's genome polymorphic markers to determine whether a particular therapy, or dose of therapy, will be effective [9].

iii. The disclosure of pharmacogenomics information's in the labels of about 100 drugs, in diverse fields such as analgesics, antiviral, cardiovascular drugs, and anti-cancer therapeutics.

iv. The use of genome sequencing to detect mutations across the entire genome simultaneously for a much larger number of diseases or conditions. Indeed, this has been shown to provide a useful differential diagnosis within 50 hours for children in the neonatal intensive care unit [10].

v. The testing of transplanted heart rejection by measuring the levels of cell-free circulating DNA from the donor organ in the recipient's blood stream. The level of this DNA correlates with the severity of the rejection event [11]. Testing of Cell-free circulating DNA is also being explored as a biomarker for cancers. Tumor cells release fragments of their mutated DNA into the bloodstream. Sequencing this DNA can give insights into the tumor and possible treatments, and even be used to monitor tumor progression [12].

vi. The availability of about 100 nucleic acid-based tests for microbial pathogens.

vii. The use of DNA sequencing in the investigation of infectious disease outbreaks, including Ebola virus, 
drug-resistant strains of Staphylococcus aureas and Klebsiellapneumoniae, as well as diagnosis of bacterial meningoencephalitis and rapidly identifying the correct therapeutic agent for the patient.

\section{Gene Editing}

Gene editing is the latest development of genetic engineering. It is a set of technologies that allow to accurately modifying the genetic information contained in the DNA of a living organism. Gene editing enables the alteration of genetic information by adding or deleting DNA sequences and by replacing the genetic code in a precise position of the genome. It is achieved through the use of nucleases called "molecular scissors". Four major gene editing technologies are currently being used; all of them are based on the use of endonucleases. These technologies are namely, the Meganucleases, the Zinc Finger Nucleases (ZFNs), the Transcription Activator-Like Effector Nucleases (TALENs) and the Clustered Regulatory Interspaced Short Palindromic Repeats (CRISPRs) [13]. While they are equally highly specific, these technologies differ in their adaptability, with the mega nucleases and ZFNs being the most difficult and technically demanding and CRISPRs being the simplest and less expensive one. Even though CRISPRs is an error-prone process and may lead to off target alterations, it is the most popular among scientists and extensive research and development is showing that the drawback can be overcome. Gene editing can be carried out in ex vivo as well as in vivo.

Translations of gene editing into medicine practice are expected to explode and some applications are already progressing among which the following:

A. For Hemophilia: Method of gene editing using a system that delivers a ZFNs and then inserts the corrected clotting factor gene to the liver of patients with hemophilia is underway. Trial enrollment is currently active at the City of Hope in California and the first patients expect to be treated in the very near future [14].

B. For HIV: A clinical trials in humans targeting the CCR5 gene, which makes a protein that HIV needs to get into human cells was carried out in 12 patients. This was the first nuclease-mediated gene editing for HIV treatment [15].
This trial started by designing zinc finger nucleases to target the CCR5 gene, for use ex vivo to knockout the CCR5 gene in immune cells collected from patients with HIV. Cells in which the CCR5 gene is knocked out were completely resistant to infection by HIV. It was also shown that these cells are able to function normally to fight infections, in contrast to cells infected with HIV.

C. Gene editing trials for patients with Cancer have recently begun in China, and a number of other trials in the US $[16,17]$.

\section{Biologics}

At the opposite of conventional chemical drugs, biological drugs or "biologics" [18] are biological products that are made of proteins, nucleic acids, carbohydrates or complex combinations of these substances. They can even be living entities such as cells and tissues. Biologic products are effective to treat, cure, prevent or diagnose diseases and medical conditions. These products are made from a variety of natural sources such as human, mice, bacteria, yeast, mammalian cell culture, avian cell culture, insect cell culture, plant cell culture, and transgenic animals and plants. Biological drugs can be human tissues, whole blood, blood derivatives or blood components, xenotransplantaion products, recombinant proteins such as insulin, human growth hormone, erythropoietin, interferon's and other cytokines to name but a few. Vaccines (preventive or therapeutic) as well as allergenic extracts, cellular therapies including the one that uses stems cells [19], gene therapy products, RNA interference [20] and antisense therapy [21], fall under the classification of "biologics" for most of the world health and pharmaceutical regulation agencies. Within the harmonious development of this new class of health care products, Monoclonal antibodies (Mabs) (humanized or human) have emerged as blockbusters of the biopharmaceutical industry after showing a significant advantage in the treatment of a variety of diseases mainly cancers. As a consequence Mabs became the hallmarks of cancer (Table 1). According to America"s biopharmaceutical research companies, in the year 2013, 65\% out of the 900 "biologics" under development, was Mabs and vaccines, respectively $37 \%$ and $28 \%$ [22].

Table 1: Hallmark of cancer therapeutic monoclonal antibodies: The top five selling therapeutic Mabs in 2015 with their target antigens and clinical indications.

\begin{tabular}{|c|c|c|}
\hline Trade Name & Product & Indication(s) \\
\hline Humira & Adalimumab anti TNF mab & Rheumatoid arthritis, psoriasis, Crohn's disease \\
\hline Rituxan & Rituximab and CD20 mab & Leukemias \& Lymphomas, lupus \\
\hline Avastin & Bevacizumab anti VEGF-A mab & Cancers \\
\hline Herceptin & Trastuzumab anti Her2Neu mab & Breast cancer \\
\hline Remicade & Infliximab anti TNF mab & Rheumatoid arthritis, Psoriasis \\
\hline
\end{tabular}


The main features that distinguish "biologics" from chemical drugs are related to molecular weight and structural complexity. This complexity is reflected in the manufacturing processes used to produce "biologics" that are by far more sophisticated, costly and technically demanding. As a consequence "biological" are less easily characterized then chemical drugs which hampered the development of their generic form or Biogenerics. Indeed the world big regulation agencies such as the FDA (the US Food and Drug Agency) and EMEA (European Medicine Agency) have been approving biosimilars in a case by case through some kind of Habeas corpus (Figure 1).

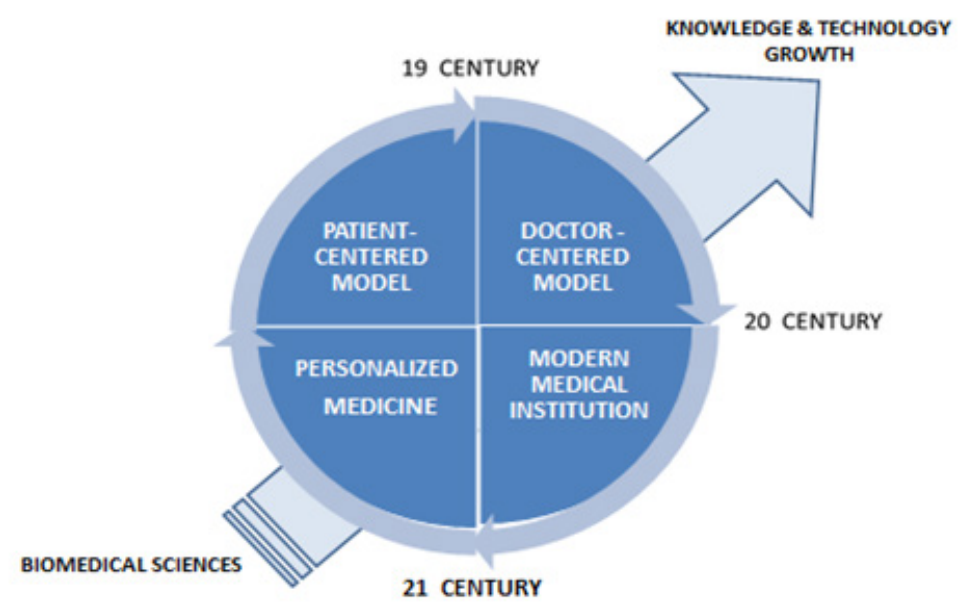

Figure 1: The new medical paradigm shift: Between the middle age and the twentieth century, the medical practice shifted from anempirical patient centered model (home family doctor) to a doctor centered, population-based and 'one drug fits all' treatment model within an established medical institution. The accumulation of tremendous medical scientific knowledge and technological advances are currently gearing the medical field toward another form of scientifically patient-centered model with focused personalized treatment and rational companion diagnostic.

No matter how fast these three technologies are making their way into the medical field, their development will always remain the underlying cause behind the shifting from the empirical 'one drug fits all' therapeutic practice to a novel type of personalized medical practice. Rational companion genetic testing will be used to back biological drug clinical efficiency by identifying the most genetically qualified patient subgroup. Precision gene editing will correct all genetic alterations associated with diseases and gene therapy should become a safe, routine procedure. The concomitant development of bioinformatics is playing a major role in accelerating the move toward the new $21^{\text {st }}$ century medical paradigm. These technologies will definitely bolster medicine in the short term. Nevertheless, the use of these new technologies is not free from ethical [23] and economic [24] issues that urgently need to be sorted out for this new paradigm to thrive.

\section{References}

1. John D (2001) Aphysical map of the human genome. Nature 409(6822): 934-941.

2. Venter JC, Adams MD, Myers EW, Li PW, Mural RJ, et al. (2001) The Sequence of the Human Genome. Science 291(5507): 1304-1351.

3. Levens D, Baranello L, Kouzine F (2016) Controlling gene expression by DNA mechanics: emerging insights and challengeBiophys Rev (3): 259-268.
4. Krüger J and Schleinitz D (2017) Genetic Fingerprinting Using Microsatellite Markers in a Multiplex PCR Reaction: A Compilation of Methodological Approaches from Primer Design to Detection Systems. Methods Mol Biol 1492: 1-15

5. Lohr JG, Adalsteinsson VA, Cibulskis K, Choudhury AD, Rosenberg M, et al. (2014) Whole-exome sequencing of circulating tumor cells provides a window into metastatic prostate cancer. Nature Biotech 32(5): 479484 .

6. Wang Z, Gerstein M, SnyderM (2009) RNA-Seq: a revolutionary tool for transcriptomics. Nature Reviews Genetics 10(1): 57-63.

7. Van der Weyden L et al. (2017) Genome-wide in vivo screen identifies novel host regulators of metastatic colonization. Nature 541(7636): 233-236.

8. http://www.resourcerepository.org/documents/1869/ understandinggenetics:adistricto

9. Relling MV, Evans WE (2015) Pharmacogenomics in the clinic. Nature 526(7573): 343-350.

10. De LigtJet, Willemsen MH, Van Bon BW, Kleefstra T, Yntema HG (2012) Diagnostic Exome Sequencing in Persons with Severe Intellectual Disability. N Engl J Med 367(20): 1921-1929.

11. De Vlaminck I, valantine HA, Snyder TM, Strehl C, Cohen G, et al. (2014) Circulating cell-free DNA enables noninvasive diagnosis of heart transplant rejection. Sci Transl Med 6(241).

12. Bettegowda c, sausen M, Leary RJ, Kinde I, Wang Y, et al. (2014) Detection of circulating tumor DNA in early- and late-stage human malignancies. Sci Transl Med 6(224). 
13. Sander JD, Joung JK (2014) CRISPR-Cas systems for editing, regulating and targeting genomes. Nat Biotechnol 32(4): 347-355.

14. http://www.prnewswire.com/news-releases/sangamo-biosciencesannounces-fda-clearance-of-investigational-new-drug-applicationfor-sb-fix-first-in-vivo-protein-replacement-platform-program-fortreatment-of-hemophilia-b-300185804.html

15. Tebas P, Stein D, Tanq WW, Frank I, Wang SQ (2014) Gene Editing of CCR5 in Autologous CD4 T Cells of Persons Infected with HIV. N Engl J Med 370: 901-910.

16. http://www.vabioethics.com/content/2016/11/24/crispr-geneediting-trials-begin-in-human-cancer-patients

17. http://www.gene-editing.org/single-post/2016/11/23/First-humantrials-in-CRISPR-gene-editing-to-combat-cancer

18. Declerck PJ (2012) Biologicals and biosimilars: a review of the science and its implications. Generics and Biosimilars Initiative Journal (GaBI Journal) 1(1): 13-16.
19. Sylvester KG, Longaker MT (2004) Stem cells: review and update. Arch Surg 139(1): 93-99.

20. Kim DH, Rossi JJ (2008) RNAi mechanisms and applications. Biotechniques 44(5): 613-616.

21. Lundin KE, Gissberg O, Edvard Smith CI (2015) Oligonucleotide Therapies: The Past and the Present. Hum Gene Ther 26(8): 475-485.

22.http://phrma-docs.phrma.org/sites/default/files/pdf/ biologicsoverview2013.pdf

23. Mathaiyan J, Chandrasekaran A, Davis S (2013) Ethics of genomic research. Perspect Clin Res 4(1): 100-104.

24. Buchanan J, Wordsworth Sand SchuhA (2013) Issues surrounding the health economic evaluation of genomic technologies. Pharmacogenomics 14(15): 1833-1847.

\footnotetext{
Your next submission with Juniper Publishers will reach you the below assets

- Quality Editorial service

- Swift Peer Review

- Reprints availability

- E-prints Service

- Manuscript Podcast for convenient understanding

- Global attainment for your research

- Manuscript accessibility in different formats

( Pdf, E-pub, Full Text, Audio)

- Unceasing customer service

Track the below URL for one-step submission

https://juniperpublishers.com/online-submission.php
} 